\title{
Implementing Total Quality Management Concepts to Land Administration System in Pakistan
}

\author{
Zahir Ali ${ }^{1,2, *}$, A. M. Tuladhar ${ }^{2}$, J. A. Zevenbergen ${ }^{2}$, Muhammad Ajmal Bhatti ${ }^{3}$ \\ ${ }^{1}$ Pakistan Space and Upper Atmosphere Research Commission (SUPARCO), P.O. Box 8402, Karachi 75270, Pakistan \\ ${ }^{2}$ Faculty of Geo-Information Science and Earth Observation (ITC), University of Twente, P.O. Box 217, 7500 AE Enschede, the \\ Netherlands \\ ${ }^{3}$ DCO Gilgit \\ *Corresponding author: drzahirali@yahoo.com
}

Received October 29, 2014; Revised November 17, 2014; Accepted November 24, 2014

\begin{abstract}
Evaluation and assessment of land administration system has been getting more attention over the last few years. Different assessment approaches have been tried across land administration systems at international level to assess the performance of these systems, but the attention is given to only those parameters which are common to all these systems. In some cases, legal and technical parameters are considered while institutional and organisational parameters got more attention in others. There have been a few efforts to standardise the procedures for assessing the performance of land administration systems at international level but no internationally accepted or standardised method is there to assess the quality of a standalone land administration system. There is a need to develop a framework for assessing the quality of a standalone land administration system in a country taking into account all its components and parameters as per quality requirements. The core objective of this paper is to develop a framework for applying the concepts of total quality management to land administration system. The case of land administration system in Pakistan is presented and discussed in this paper. The quality improvement guidelines are then developed within the broad context of total quality management for improving the quality of land administration system in Pakistan, which was presupposed as deteriorated.
\end{abstract}

Keywords: land administration system, quality assessment, total quality management

Cite This Article: Zahir Ali, A. M. Tuladhar, J. A. Zevenbergen, and Muhammad Ajmal Bhatti, "Implementing Total Quality Management Concepts to Land Administration System in Pakistan." American Journal of Rural Development, vol. 2, no. 4 (2014): 74-80. doi: 10.12691/ajrd-2-4-3.

\section{Introduction}

The quality of land administration system (LAS) can be evaluated through several multi-dimensional approaches. These evaluation measures can further help to improve the quality of existing LAS as per quality requirements. However, the main aim pursued in an evaluation should determine what to measure and how to measure it? It is important to keep in mind that the performance of any system can be measured only if the quality parameters and indicators of the existing system are known first. These quality parameters and indicators are also varying from system to system depending upon the structure of existing LAS, users' needs, social and cultural norms and values of a society in which the LAS is being practised.

In all these previous studies, the quality of LASs was measured across different land administration systems that were in use in different countries and the attention was given to only those quality parameters which were common in all these LASs. All previous research studies considered different components of LAS including legal, technical, social, organisational, and political component in order to evaluate these components. Therefore, due to diverse nature of LAS, a comprehensive method is thus required to analyse the quality of an existing LAS of a country exclusively by considering all its components through an assessment framework for better assessment and analysis.

The analysis of different components calls for a holistic response before going to suggest further suggestions for improvements. Therefore, a conceptual framework is thus required to analyse these components for the existing LAS before going to define quality improvement guidelines. This quality assessment framework will further help to model the changing role of existing LAS within country's social, cultural norms and values as per users' needs and quality requirements. However, the basic concepts of quality and total quality management (TQM) should be considered in this connection so that a holistic approach could be followed to analyse and improve the quality of existing LAS. No work has been carried out in this regard to present a set of quality indicators for assessing the quality of existing LAS first and then develop quality improvement guidelines for a standalone LAS.

The intention of this paper is to define the concerned indicators and variables for the elements of LAS from technical and institutional perspectives to assess their quality. The case of LAS in Pakistan is presented and discussed by collecting both qualitative and quantitative 
data in the urban and rural areas of Peshawar and Swabi districts of the Khyber Pakhtunkhwa province of Pakistan.

\section{Theoretical Background}

Many definitions of quality are available in the literature. Quality is the degree to which an object (e.g. process, product, or service) satisfies a specified set of attributes or requirements (Cooper and Fisher, 2002). According to the American Society for Quality (ASQ), "Quality denotes an excellence in goods and services, especially to the degree they conform to requirements and satisfy customers" (Chandrupatla, 2009). According to Bilich and Neto (2000) "quality, as a macro function of institutions, must be present in the day-to-day running of an institution, in aspects such as establishment of policies, the decision process, selection of personnel, allocation of resources, definition of priorities and service delivery to satisfy customer requirements”. Quality is an on-going process that has to be so pervasive throughout the institution that it becomes the philosophy and culture of the whole institution. All institutions and each department within the institution need to adopt the same strategy, to serve the customer with even better quality, lower cost, quicker response and greater flexibility (Schonberger, 1990).

A hierarchical process of quality includes the development of inspection through to quality control, within the context of systems of quality assurance under the wider management approach of total quality management (Das Mulm, 2009). Oakland (1993) defines total quality management as "an approach to improving the competitiveness, effectiveness and flexibility of a whole organisation". In this way TQM can play an important role in improving quality of any organisation as it considers the whole system including all the processes and workforce.

Total Quality Management (TQM) presupposes that its principles will be applied to all levels of the organisation of the enterprise. This implies that it must be incorporated not only in every product or service provided (as many people may think) but also to all levels of activity. Total Quality Management can be developed in four stages as shown in Figure 1 (Lakakis et al., 2000);

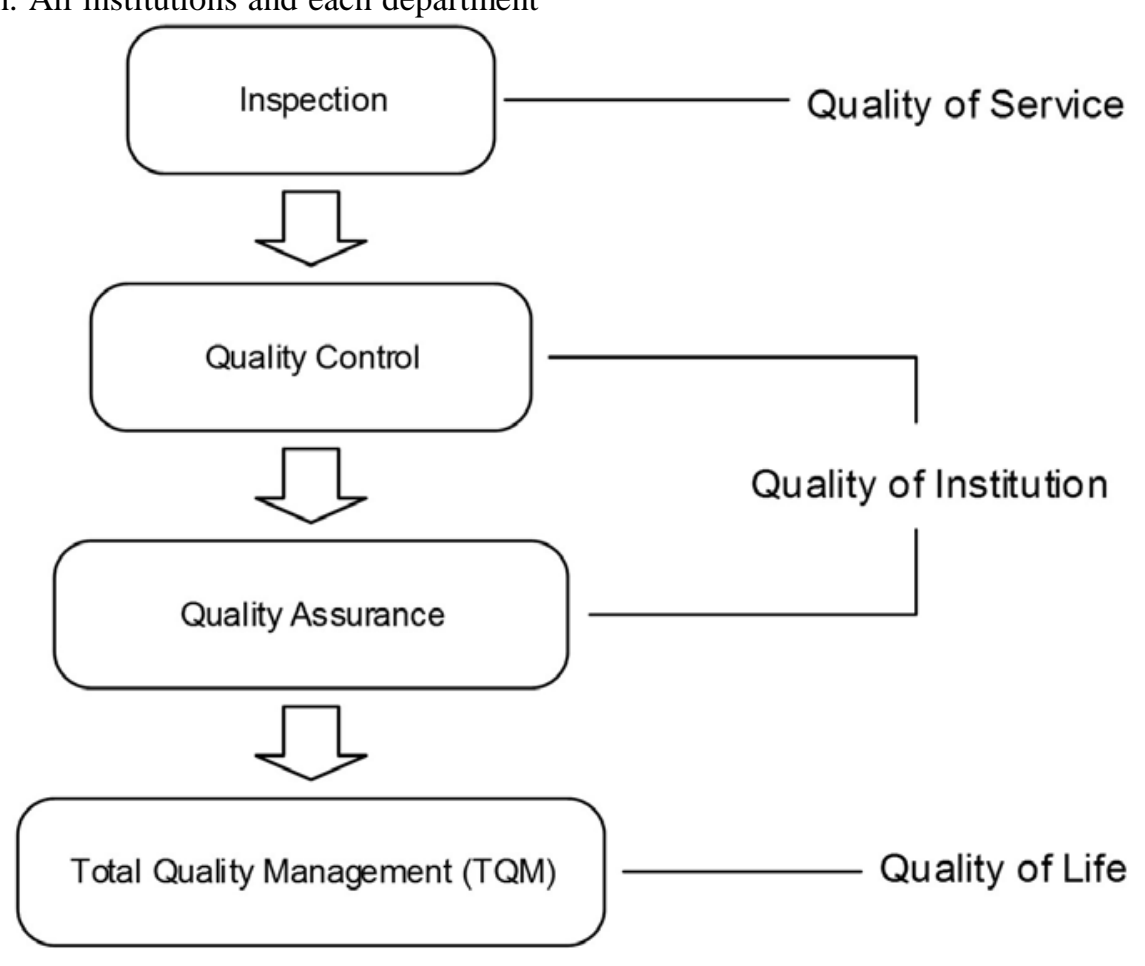

Figure 1. Stages of TQM development (Oschman, 2004)

Inspection is the comparison of the characteristics of the final product or service to the technical specifications. This will mostly concern with the operational level where most of the products or services delivered at the users' end.

Quality Control (QC) follows inspection and is the total of operational and technical procedures which can confirm the quality of a product or service according to specifications. From LAS point of view, it will focus on both the institutional and technical problems and issues at management level so that the quality of the product or service can be measured at this stage.

Quality Assurance (QA) is the total of pre-programmed or systematic actions and procedures necessary for ensuring that a product or service fulfils and will continue to fulfil certain specifications. In LAS, this plays an important role at the policy level where a set of rules and regulation must be defined to ensure the quality of the product or service.

Total Quality Management (TQM) is the total of activities and methods used by an enterprise in order to fulfil the requirements of a client with the least cost, emphasis given on the link between TQM and QA. For LAS, it is most important to develop TQM concept at regular basis so that new advancements in technology and customers' needs analysis could be brought into consideration for improving the quality of existing system.

\section{Study Area and Methodology}

The land administration organisation called Board of Revenue (BOR), in the Khyber Pakhtunkhwa (formerly 
called NWFP) province of Pakistan was chosen in this study for assessing the quality of the existing LAS. The BOR offices at the Peshawar and Swabi districts of KP province were visited during the field visits (Ali et al., 2010; Ali et al., 2013). The locations of these districts on the provincial map are shown in Figure 2. The collected data comprised interviews with all the stakeholders including law professionals, land owners, real estate agencies, revenue courts and banks officials, and the BOR officials and staff. Meetings and interviews were arranged with the BOR officials at the headquarters in Peshawar city. This included; Senior Member Board of Revenue (SMBR), Member Board of Revenue (MBR), and Director Land Records (DLR). The other BOR officials such as Tehsildar, Naib Tehsildar, and Patwari were also interviewed in these two districts to note down their concerns about the existing system.

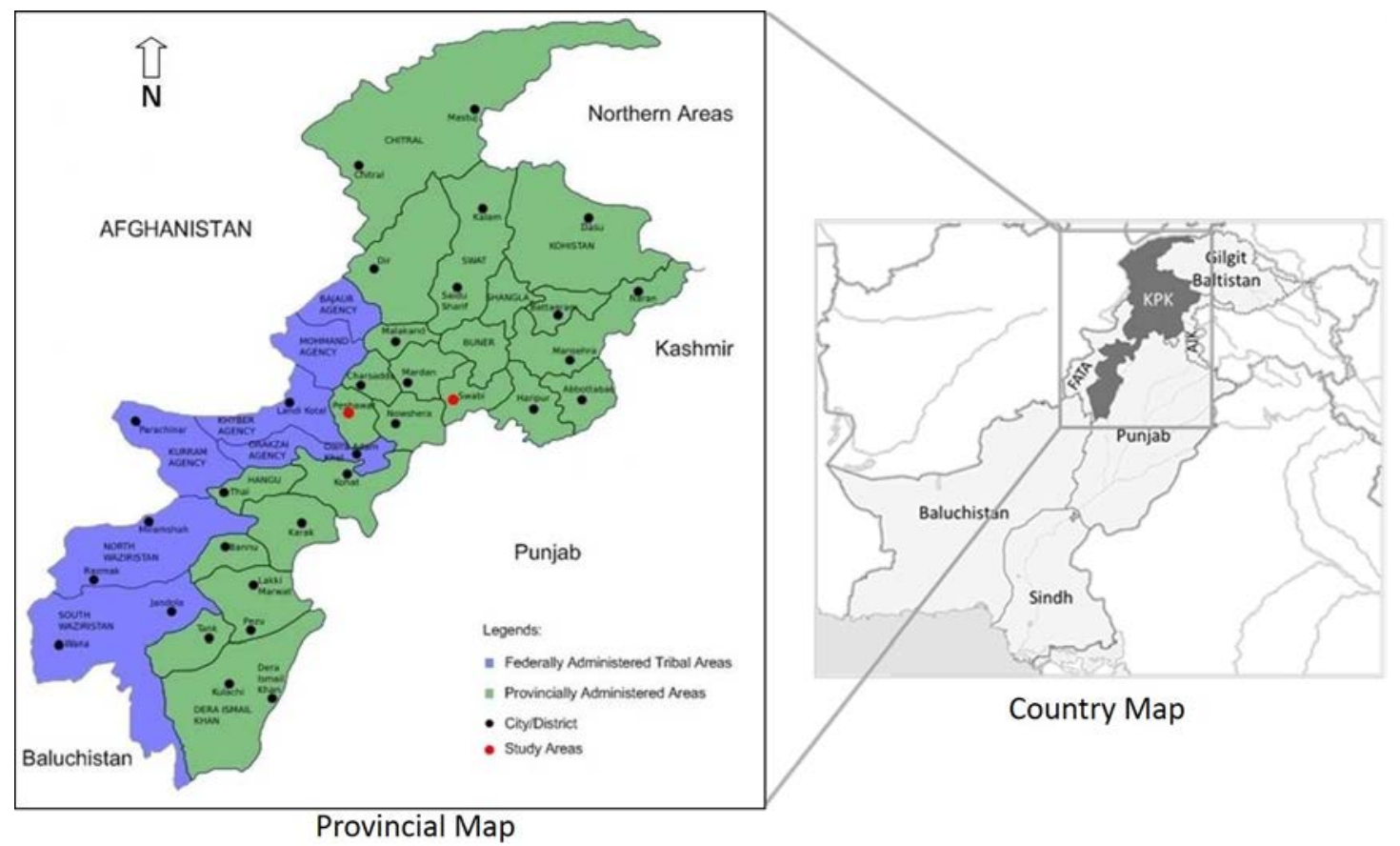

Figure 2. Location of fieldwork study areas

In case of land administration systems, it is most important to develop quality improvement guidelines by considering all the organisational levels so that all the processes and stakeholders could be brought into consideration to improve its quality of these systems. Therefore, all these quality improvement guidelines must be developed within the pyramid of organisational levels by adopting systematic process of quality under the wider management approach of TQM. A framework for improving the quality of LAS in order to draw these quality improvement guidelines is shown in Figure 3.

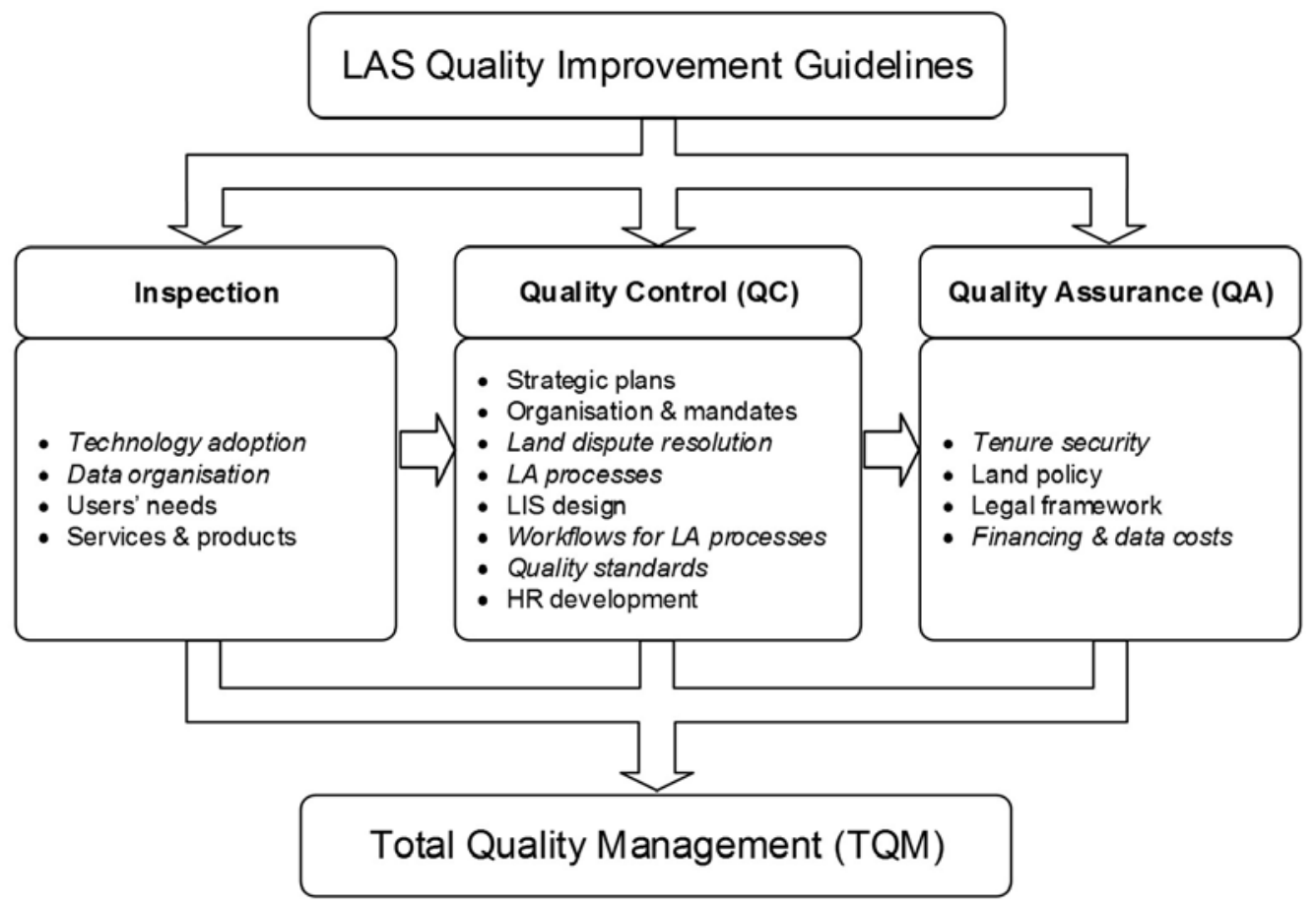

Figure 3. LAS Quality Improvement Framework 


\section{Quality Improvement Guidelines}

Based on the analysis and results obtained from two case studies (Ali et al., 2010; Ali et al., 2013), a set of quality improvement guidelines is developed for improving the quality of deteriorated LAS in Pakistan. The design of these quality improvement guidelines is varying from system to system depending on the existing situation of LAS within the country in which the system is being examined.

\subsection{Quality Improvement Guidelines on Quality Inspection (QI)}

Quality improvement guidelines dealing with QI stage of TQM in LAS are treated by the stakeholders at operational level. The guidelines on the QI side are;

Adopting New Technology: Appropriate GIS technology should be adopted to map and maintain geometrical cadastral information within strategic objectives (FIG, 2005). Cadastral information can be collected and cadastral parcel boundaries can be surveyed with less labour, time, and cost as compared to the old fashioned field surveying technique by integrating global positioning system data, remote sensing imagery, and existing cadastral maps through participatory geographic information system technique (Ali et al., 2012). Technology must be adopted to make the system process quick and provide fast services at the users' end to fulfil land market needs for enhanced economy generation and users' satisfaction. There should be easy ways for sorting, accessing, and disseminating this data at local level for the users to produce efficient land market.

Organising Land Data: On data organisation side, there is a need to sort out adequate data and information models for sustainable land information management (van der Molen, 2006). Land records should be maintained at local level and the copies should be also kept at central level so that original record could be recovered in case of any troubles in land records at local level or any lost due to other disasters such as flood and fire etc. Similarly, the introduction of front desk facility and one window operation can help the stakeholders to access their land records more easily at all levels.

Analysing Users' Needs: In order to improve the performance of LA system, users' needs should be analysed on regular basis and a list of different stakeholders such as professional (lawyers, financial institutions, etc.) and non-professionals (land owners, real estate agents, etc.) must be created and maintained to understand their needs. The needs or requirements of users can be captured in a variety of ways such as direct discussion or interviews, surveys, focus groups, users' specifications, observation, warranty data, field reports etc. (Crow, 2002). The use of mass media can also help in attracting users' attention and giving their inputs through different questionnaires and pamphlets as well as other media programs. The understanding of these users' needs can be then summarised in a product or service to satisfy their needs.

Improving Services and Products Delivery: All the services and products are partially delivered to users at local level. These services and products delivery should be made more efficient by providing sufficient land offices and infrastructure by land administration agency. The organisational capacity should be assessed in terms of human resource and building infrastructure to provide all the products and services at local level to all the stakeholders. This will also help the land agency to collect the taxes and other revenue generated through land transactions as well as to manage the land records effectively. The use of information technology such as internet and web services can be used to improve the product and service delivery. Similarly, the front desk services can also help in improving the quality of services at users end to get their desired products in an easier way. Moreover, the existence of all cadastral information in digital form can help to store, update, and disseminate all the land related data in an efficient manner.

\subsection{Quality Improvement Guidelines on Quality Control (QC)}

Quality improvement guidelines concerning the QC stage of TQM in LAS are mostly covered by the stakeholders at management level. The quality improvement guidelines on the QC side include;

Developing Strategic Plans: Strategic and development plan should be developed for the adoption of GIS technology in existing LAS to improve the overall performance of the system. Similarly, the ICT-business strategy for cadastral and land registration would greatly support the expansion of a land administration system's spatial-ICT based services, particularly in the area of land markets and valuation (Burns et al., 2007). The strategic targets should be defined in this regard and strategic plan should be published on regular basis to achieve the predefined objectives and targets. A collective strategic approach should be adopted to include a number of fundamental principles, issues, and components which are required in the formulation of a land information system (LIS) strategic plan for a jurisdiction (Sedunary, 1993; Tuladhar et al., 2002). A strategic plan is thus required as no such plan was found for adopting GIS technology in the existing system. Furthermore, all the objectives and strategies should be regularly reviewed with changing role of technology and users' needs.

Defining the Mandates of Land Administration Organisation: The organisational structure of LA agency in Pakistan is found good for execution of work processes with its mandates for land administration and management at top management level. However, the allocation of tasks and responsibilities for BOR personals need to be revised at local level. The management of customer relation should be also clearly defined in these mandates to meet the demands of all the stakeholders. Similarly, the role of other sectors such as academic sector and private sector (FIG, 2010a) should be clearly defined in the mandates of land administration organisation. The academic sector can help on the capacity building side through organising refresher and training courses for the land agency people whereas the involvement of private sector can help to reduce the cost and time for carrying different tasks that can be easily done by them.

Improving Land Dispute Resolution Mechanisms: The relationship between land and dispute is extraordinarily complex. Addressing land issues 
effectively demands a broad, integrated, and interdisciplinary approach. Lack of accurate information about land rights and other land issues can fuel confusion and suspicion that can lead to land disputes. Early public information and education campaigns about land-related issues can help to clarify issues and correct false assumptions (USAID, 2005). While interviewing the land owners in the field it is observed that the existing mechanisms for resolving land disputes are very complicated and time consuming. Therefore, land dispute resolution mechanisms should be made more simple and low cost for the land owners by introducing alternative approaches such as negotiation, arbitration and mediation. This will help to resolve land disputes at local level through mediation between the concerned parties and involving local government and local citizens.

Improving Land Administration Processes: Land administration processes should be made clear and simple which can be easily understood by a common citizen. These LA processes should be transparent and effective in operation to increase confidence level among all the people. The existing land administration processes can be made simple, cheap, and transparent by considering process design, process simulation, and benchmarking techniques (Radwan et al., 2001). The time required for updating information in land register and cadastral map should be shortened as per changing societal needs and users' requirement. The existing traditional boundary demarcation process can be improved by introducing a photogrammetric technique which uses aerial photographs or high resolution satellite images as an alternative for spatial data acquisition. In this case most measurements can be done in the office (Tuladhar, 2005). The existing discipline-oriented surveying technique can be also replaced by adopting the methodology-oriented integrated technique in which the parcels boundaries can be delineated and other cadastral information can be collected more efficiently (Ali et al., 2012). Similarly, the registration process can be improved by re-engineering it and introducing front desk and one window operation facility.

Introducing new Concepts in Land Information System Design: The new concepts in information system for data modelling and process modelling should be introduced in existing LAS. For this purpose, the existing processes in land information system including; land surveying, mutation process, and land registration process must be re-engineered as per user/quality requirements and new developments in the field of information technology. On system development side, the cadastral modelling, such as Land Administration Domain Model (LADM), is considered as a basic tool for facilitating appropriate system development and forming the basis for meaningful communication between different (parts of the) systems (van Oosterom et al., 2006). On the data capture side, due to advancements in Geo-ICT, the traditional surveying concept has taken on a new shape from discipline-oriented technologies such as geodesy, surveying, photogrammetry, and cartography into a methodology-oriented integrated discipline of geoinformation science. A participatory geographic information system (PGIS) combined with remote sensing images is quite interesting for gathering quality data with the involvement of land owners, tenants and other stakeholders (Ali et al., 2012).

Developing Workflows for Land Administration Processes: Core land administration functions are the registration of rights in land and the survey and mapping of the boundaries of the extent of these rights. A key determinate in the efficiency of a land administration system is the institutional structure that supports these core functions (Burns et al., 2007). In this regard, the internal and external information flow for allocation of tasks and responsibilities to managers within the land administration organisation should be appropriate and clearly specified for better performance of LAS. Standard operating instructions for each step of workflow should be developed and implemented as a part of total quality framework. GIS and database technologies are to be employed for land data processing, updating, storing and dissemination. The integration and sharing of georeferenced data becomes more and more crucial, and there is an increasing need for efficient and reliable data exchange (Steudler, 2006). In this context, OpenGIS and GML/XML are important tools for efficient and transparent data access in different land administration activities.

Defining Quality Standards: Since databases of LAS reside in different organisations and data are gathered using different sources, the data quality needs to be transparent for users and stakeholders. Different elements of geographic data quality must be defined like positional quality, temporal quality, completeness, data status, logical consistency, lineage and timeliness (FGDC, 1994; Stanek and Frank, 1993). A set of national data standards for service quality and spatial/non-spatial data quality standards should be defined by the land administration agency based on international standards such as ISO. These quality standards should be evaluated on regular basis to incorporate users' need and quality requirements with changing role of technology in a society. In this regard, the coverage vs. accuracy option must be considered while converting the existing manual cadastral data into digital format to reduce the required cost and time. Similarly, the private sector can be involved in land related activities (Burns et al., 2007) so that the work load would be shared and land administration agency can deliver their services efficiently.

Building Human Resource Capacity: Land Administration is about individuals or people - from politicians, senior professionals and managers, middle managers and administrators, to office and field personnel. All the players in the system need to have some understanding of the overall system as well as more detailed and specific skills, which need to be developed. For this purpose, the capacity assessment and development in the area of land administration should be analysed at all three levels (societal, organisational, individual level) of capacity building through a conceptual framework (Enemark and Williamson, 2004). At societal level, it looks at issues and principles of policy and legal frameworks, tenure, and administration systems. At organisational level, it looks more closely at enabling good governance, institutional strengthening, consideration of spatial data infrastructure principles, and development of a professional body. At individual level, it deals with the professional and technical competence, 
capacity needs, and educational resources. This can be achieved through collaboration with academic and research institutions through short courses and training opportunities in land administration.

\subsection{Quality Improvement Guidelines on Quality Assurance (QA)}

Quality improvement guidelines relating to the QA stage of TQM in LAS are handled by the stakeholders at policy level. The quality improvement guidelines on the QA side are;

Improving Tenure Security: The nature and extent of rights in land should be clearly defined for the land owners and different campaigns should be launched to educate common citizens about their rights in land and tenure security. Tenure security also can be enhanced by exploring innovative arrangements in land management through simplified procedures and inter-linking cadastral and Land Information Systems (LIS) to provide land information at local level to users in an efficient manner. Similarly, alternative land transfer techniques (land delivery, transactions, etc.) should be developed that can be used by low-income people to get easy access to land information to remove the hindrances to efficient land market and access to formal credits (UN-HABITAT, 2003). Furthermore, negotiation mechanism should be adapted to resolve some of the tenure issues by involving local community and land owners at local level.

Developing Land Policy: The land policy must describe how the government intends to deal with the allocation of land and land related benefits to facilitate the implementation of rules for land tenure and land tenure security, the functioning of the land market, land use planning and development, land taxation, management of natural resources, land reform, etc. (FIG, 2010b). The land policy framework should recognise the growing complexity of rights, restrictions and responsibilities relating to land, and consequent demands on land administration infrastructures (Williamson, 2001). In case of Pakistan, a comprehensive land policy is needed to address all land related issues. Different types of formal and informal rights in land must be clearly defined so that all the stakeholders can easily understand their land rights.

Re-structuring Legal Framework: The legal framework should be re-structured to provide enough clearness and transparency on land holdings and rights. This can be done by re-analysing the existence mechanism and laws for allocating land rights, land use, and land valuation. The whole structure of land valuation and taxation for gathering revenues should be defined so that the valuation method should fit to the societal needs. For this purpose, an evaluation system must be evolved to take into account the impact of taxation on use of land and land markets by involving land owners and other stakeholders from real estate agencies. The legislation governing land administration also needs to be reformed so that new laws should be included and the out-dated laws could be removed. Furthermore, the division of the jurisdiction of revenue court and civil court must be clearly defined so that the stakeholders can easily contact the concern court in case of their land disputes.

Structuring Financing and Data Costs: Financial mechanisms should be improved by improving the tax collection process and introducing costs recovery concept in the existing system through offering different types of products and services to the users. The fees and costs structure should be considered in such a way that vulnerable sections of population may not be excluded because of the cost factor. International experience can be studied for financial sustainability of existing LAS (Burns et al., 2007) that typically involve investigation of a number of factors such as appropriate fee and tax structures (including the balance of transaction-based) and annual fees and taxes, effectiveness of collecting fees and taxes, fiscal policy concerning the raising of revenue at the various levels of government, alternatives for land administration service delivery and costing of these alternatives, budgetary support for land administration at various government levels, and the availability of funds from government and donor agencies to support the initial development of LAS.

\section{Conclusions}

The quality situation of existing LAS in Pakistan is deteriorated and needs urgent attention (Ali and Nasir, 2010a,b). A quality improvement framework is developed to provide a line-of-action for designing a set of quality improvement guidelines for all the elements of LAS especially the important ones to improve the system's quality. Since, the components of quality process include the development of 'Inspection' through to 'Quality Control' within the context of 'Quality Assurance' under the wider management approach of TQM. Therefore, the selection of these quality improvement guidelines is carried out within the broad context of TQM. All the quality improvement guidelines are designed on the basis of results obtained from the case study carried out in Pakistan.

\section{Reference}

[1] Ali, Zahir and Nasir, Abdul. (2010a) "Land Administration System in Pakistan-Current Situation and Stakeholders' Perception". FIG Congress 2010: Facing the Challenges-Building the Capacity, 1116 April, Sydney, Australia.

[2] Ali, Zahir and Nasir, Abdul. (2010b) "Land administration: Reliability is the need of the hour". GIS Development-The Global Geospatial Magazine, Noida, India. 14 (5). pp. 30-32.

[3] Ali, Zahir, Tuladhar, A. M. and Zevenbergen, J. A. (2010) "Developing a Framework for Improving the Quality of a Deteriorated Land Administration System Based on an Exploratory Case Study in Pakistan". Nordic Journal of Surveying and Real Estate Research, Vol. 7 (1), pp. 30-57.

[4] Ali, Zahir, Tuladhar, Arbind and Zevenbergen, Jaap. (2012) "An integrated approach for updating cadastral maps in Pakistan using satellite remote sensing data". International Journal of Applied Earth Observation and Geoinformation, Vol. 18 (August2012), pp. 386-398.

[5] Ali, Zahir, Zevenbergen, Jaap and Tuladhar, Arbind. (2013) "Quality assessment of the land administration system in Pakistan". Journal of Spatial Science, Vol. 58 (1), pp. 119-146.

[6] Bilich, Feruccio and Neto, Annibal Affonso. (2000) "Total quality management: quality macrofunction model for banks". Total Quality Management, Vol. 11 (1), pp. 5-15.

[7] Burns, Tony, Grant, C., Nettle, K., Brits, A. and Dalrymple, K. (2007) "Land Administration Reform: Indicators of Success and Future Challenges". Agriculture and Rural Development Discussion Paper 37, Land Equity International Pty Ltd, Wollongong, Australia. 
[8] Chandrupatla, Tirupathi R. (2009) "Quality and Reliability in Engineering", Cambridge University Press. p. 326

[9] Cooper, J. and Fisher, M. (2002) "Software Acquisition Capability Maturity Model (SA-CMM)", Carnegie Mellon University, PA: Software Engineering Institute, Pittsburgh.

[10] Crow, Kenneth. (2002) "Customer Focused Development with QFD". DRM Associates. (16 August 2010). http://www.npdsolutions.com/qfd.html

[11] Das Mulm, Abhiman. (2009) "Quality Concepts".

[12] FGDC. (1994) "Content Standards for Digital Geospatial Metadata"(FGDC-STD-001-1998), Federal Geographic Data Committee, Washington, D.C.

[13] FIG. (2005) "Innovative IT for Land Administration", FIG Commission 7, Symposium on Innovative Technology for Land Administration, Madison, Wisconsin, USA.

[14] FIG. (2010a) "Institutional and Organisational Development: A Guide for Managers", FIG Publication; 47, International Federation of Surveyors (FIG), Copenhagen, Denmark. p. 36.

[15] FIG. (2010b) "Land Governance in Support of The Millennium Development Goals", FIG Publication; 45, The International Federation of Surveyors (FIG), Copenhagen, Denmark. p. 39.

[16] Lakakis, K., Savvaidis, P. and Ifadis, I. (2000) "The implementation of Quality Assurance in the Hellenic National Cadastral Projects". Athens-2000 Workshop of FIG-Com 3 "Spatial Information Management-Experiences and Visions for the 21st Century", 4-7 October, Athens, Greece.

[17] Oakland, J.S. (1993) "Total Quality Management: The Route to Improving Performance". Second Edition, Oxford, ButterworthHeinemann.

[18] Oschman, J. J. (2004) "A Framework for the Implementation of Total Quality Management in the South African Air Force". Department of Public Administration and Management, PhD Thesis, p. 575, University Of South Africa, Pretoria, Gauteng.

[19] Radwan, M. Mostafa, Onchaga, Richard and Morales, Javier. (2001) "A structural approach to the management and optimization of geo-information processes". 41, European Organization for Experimental Photogrammetric Research (OEEPE), Frankfurt am Main, Geodäsie, Bundesamt für Kartographie und.
[20] Schonberger, Richard. (1990) "Building a chain of customers: linking business function to create a world-class company", The Free Press, New York. p. 349.

[21] Sedunary, Mervyn E. (1993) "A strategic approach to land information management". Computers, Environment and Urban Systems, Vol. 17 (3), pp. 243-251.

[22] Stanek, H. and Frank, A. U. (1993) "Data Quality-Necessary Complement for GIS Based Decision Making". 25th International Symposium: Remote Sensing and Global Environment Change, Graz, Austria.

[23] Steudler, Daniel. (2006) "Swiss cadastral core data modelexperiences of the last 15 years". Computers, Environment and Urban Systems, Vol. 30 (5), pp. 600-613.

[24] Tuladhar, A. M. (2005) "Innovative use of remote sensing images for pro poor land management". Secure land tenure: new legal frameworks and tools in Asia and the Pacific, Bangkok, Thailand, International Federation of Surveyors (FIG).

[25] Tuladhar, A.M., Krishna Raj, B.C. and Budhathoki, Nama Raj. (2002) "Towards strategic planning for building land information system LIS in Nepal". 23rd Asian Conference on Remote Sensing, ACRS 2002, 25-29 November, Kathmandu, Asian Association on Remote Sensing (AARS); Survey Department HMG.

[26] UN-HABITAT. (2003) "Handbook on best practices, security of tenure and access to land: implementation of the Habitat agenda", UN-HABITAT, Nairobi. p. 116.

[27] USAID. (2005) "Land and Conflict-A Toolkit for Intervention", US Agency for International Development (USAID), Washington, DC. p. 41.

[28] van der Molen, Paul. (2006) "Unconventional approaches to land administration: the need for an international research agenda". 5th FIG regional conference for Africa: promoting land administration and good governance, 8-11 March, Accra, Ghana.

[29] van Oosterom, Peter, Lemmen, Christiaan, Ingvarsson, Tryggvi, van der Molen, Paul, Ploeger, Hendrik, Quak, Wilko, Stoter, Jantien and Zevenbergen, Jaap. (2006) "The core cadastral domain model". Computers, Environment and Urban Systems, Vol. 30 (5), pp. 627-660.

[30] Williamson, Ian. P. (2001) "Land administration "best practice" providing the infrastructure for land policy implementation". Land Use Policy, Vol. 18 (4), pp. 297-307. 